\title{
THE GLOBAL ROCK ART DATABASE: DEVELOPING A ROCK ART REFERENCE MODEL FOR THE RADB SYSTEM USING THE CIDOC CRM AND AUSTRALIAN HERITAGE EXAMPLES
}

\author{
R. A. Haubt ${ }^{\text {a }}$ \\ ${ }^{\text {a }}$ PERAHU, School of Humanities, Griffith University, Southport campus, Australia - robert.haubt@griffithuni.edu.au
}

KEY WORDS: rock art, heritage management, CIDOC CRM, data centralization, ontology, domain model

\begin{abstract}
:
The Rock Art Database (RADB) is a virtual organisation that aims to build a global rock art community. It brings together rock art enthusiasts and professionals from around the world in one centralized location through the deployed publicly available $R A D B$ Management System. This online platform allows users to share, manage and discuss rock art information and offers a new look at rock art data through the use of new technologies in rich media formats. Full access to the growing platform is currently only available for a selected group of users but it already links over 200 rock art projects around the globe.

This paper forms a part of the larger Rock Art Database (RADB) project. It discusses the design stage of the RADB System and the development of a conceptual RADB Reference Model (RARM) that is used to inform the design of the Rock Art Database Management System. It examines the success and failure of international and national systems and uses the Australian heritage sector and Australian rock art as a test model to develop a method for the RADB System design. The system aims to help improve rock art management by introducing the CIDOC CRM in conjunction with a rock art specific domain model. It seeks to improve data compatibility and data sharing to help with the integration of a variety of resources to create the global Rock Art Database Management System.
\end{abstract}

\section{INTRODUCTION}

The Rock Art Database (RADB) is a rock art heritage project at the Place, Evolution and Rock Art Heritage Unit (PERAHU) at Griffith University and was established in 2012. The project aims to bring members of the global rock art community together in one centralized online platform to share and discuss rock art information. The deployed RADB Management System offers a tool to a wide range of users to collect, manage and disseminate rock art data through specialised functionalities in rich digital media formats.

The original idea for the RADB grew out of a $\mathrm{PhD}$ project that looked into the use of new technologies within Australian rock art research. The project's research data was managed in a purpose build repository that was designed to allow for the management and presentation of a wide variety of digital data formats. As more and more data was accumulated the system needed to be redesigned and eventually lead to the idea for a global rock art database.

A proof of concept model was deployed in January 2014 and made available for the general public but full access is currently limited to a small test group of users. The system is still in its proof of concept stage but is already experiencing increasing usage from rock art enthusiasts and professionals from around the world. With over 200 project entries to date the site receives up to 40 unique visitors per day.

This paper focuses on the development of a conceptual rock art reference model that is used to inform the design of the global online platform. The framework uses Australian rock art and the Australian heritage sector as a test model. The model is then placed and tested for its adequacy within a greater global heritage context.

\section{BACKGROUND TO THE RADB PROJECT}

\subsection{Rock Art}

2.1.1 The Need for Rock Art Preservation: Rock Art is a repository of memory and a testament to over 30.000 years of human activity including interactions with peoples and the environment (see Aubert, 2014; Mark, 2011). Sites are amongst the most vulnerable due to the impact of climate change, expansion of urban areas but also vandalism (UNESCO World Heritage Centre, 2010). It is becoming more and more important to develop conservation and preservation methods as more and more rock art sites are being lost due to natural and cultural threats. A centralized register could assist with the collection of rock art data and help improve understanding of rock art and preservation issues.

2.1.2 Past Efforts to Centralize Rock Art Data: The idea of centralizing heritage data is not new. Worldwide projects exist that aim to bring together heritage data from a variety of projects each with their respective aims and objectives. Such projects include UNESCO's World Heritage List, Google Maps, Google Earth, Google Cultural Institute, The Global Heritage Fund or Cyark to name just a few. While all these projects focus on different forms of data centralization, data management or data presentation, rock art related information is scarce and the little information that does exist is often difficult to find (eg Whitely, 2011). A system that focuses on identifying rock art related issues is still missing.

In 1997 the Rock Art Research journal published an article proposing the development of such a missing International Rock Art Database (Walt, 1997). The article outlines the basic concept of what such a system could look like but no publicly available system was ever deployed and the state of the system remains unclear. More than a decade later in 2010, experts again pick up on the idea and propose the development of a UNESCO World Rock Art Archive to establish a digital archive to 
conserve sites on a global scale (Unesco World Heritage Centre, 2010). But yet again no such system has been implemented.

Rock art researchers around the world have been asking for centralized systems for the last few decades. While a number of systems such as the Trust for African Rock Art (TARA), the South African Rock Art Digital Archive (SARADA) or the Mirarr Project have been developed for specific rock art projects and locations, a system that encompasses national and international sites is still missing.

In 2011 the Director of the Place, Evolution and Rock Art Heritage Unit (PERAHU) at Griffith University once again called for a centralized database, this time asking for the development of a national Australian rock art register (Mark, 2011). Australia has over 100.000 rock art sites that are important heritage places to Indigenous and non-Indigenous Australians. Many of these sites have not been documented or recorded and it is becoming increasingly important to develop conservation models to protect and preserve these sites for future generations to come. Threatened by natural and cultural agents more and more sites are being lost (Foster, 2011). But yet again no national Australian rock art register has been established.

The RADB aims to fill the gap of such a missing system. It aims to provide a tool that allows sharing and managing of rock art data on a local, national and global scale using Australian rock art as a test model for its proof of concept design.

\subsection{Placing Rock Art within the greater heritage sector}

In order to build a system that is flexible enough to allow for integration and sharing of data within a variety of international projects the RADB System places and tests Australian rock art within a national and global heritage context.

2.2.1 The greater heritage sector: The heritage sector is no longer limited to classic heritage fields such as museum studies, anthropology or archaeology but overlaps with other fields such as computer sciences, natural sciences or engineering. New interdisciplinary collaborative networks help to improve our understanding of the world but also pose new challenges. Different terminologies, discipline specific languages and methodologies can cause communication problems and ultimately interfere with the understanding and interpretation of shared data. It is becoming increasingly important to develop standards that allow us to share information in a common language and we need to reach for international standards through for example the International Organisation for Standardization (ISO) or other authoritative bodies (Fidler, 1997; Lock, 2003). Complying with such a common language would not only mean that data could be understood by other professionals, it would also assist with establishing quality frameworks, ensuring compatibility, integration of larger systems and ultimately assist with a better understanding of the world as envisioned in Gore's Digital Earth (Gore, 1998).

In order to develop the framework for the RADB we need to take a closer look at existing systems on a local and international scale and ask the following questions.

- What systems exist?

- What systems are being used?

- What can we learn from the success and failures of these systems?

- How does this apply within the rock art context?
2.2.2 The use of reference and domain models in heritage applications: UNESCO's International Council on Monuments and Sites (ICOMOS) developed such a tool for heritage documentation in 1996 under the Documentation Standards Working Group. The resulting document was the CIDOC Conceptual Reference Model (CRM) (ICOM/CIDOC Document Standards Group, CIDOC CRM Special Interest Group, 2015, p. i). The group now consists of professionals from multicultural backgrounds in interdisciplinary fields from physicist to archaeologists. The Conceptual Reference Model finds applications in a range of fields from libraries to heritage archives (Stead, 2008).

In 2006 the CIDOC CRM became the ISO 21127:2006 standard and has since been used in a variety of applications. Recent international projects include The Digital Library (DL), UNESCO's Silk Road Project, Europeana and Arches. Each of these projects offers a centralized, interdisciplinary and multicultural data management approach. While catering to individual project needs all systems are compatible through the use of the CRM (Vileikiis, 2012; Doerr, 2011; Carlisle, 2014; European Commission Information Society and Media, 2011).

2.2.3 The use of reference and domain models in Australian heritage applications: While the CRM is gaining popularity for the use in big international projects Australian heritage archives seem to fall behind. It is difficult to assess the Australian heritage system with its highly decentralized 36 government and 13 non-government heritage bodies. But it is evident through the latest State of the Environment Reports that an appropriate tool to manage heritage data is clearly missing (Department of the Environment, 2011; OCSE, 2012; NSW EPA, 2012; NT EPA, 2013; QLD EHO, 2011; SA EPA, 2008; EPA TAS, 2009; CES VIC, 2013; WE EPA, 2007).

More recently national projects such as the Humanities Networked Infrastructure (HuNI), Australian Museums Online (AMOL) and the Federated Archaeological Information Management System project (FAIMS) have started to integrate the CIDOC CRM but little output has been generated to date (Mason, 2012; HuNI, 2015; Verhoeven, 2013; Iworx Ltd. Greece, 2015; Richards, 2015; Ballsun-Stanton, 2012).

Systems such as the Australian Heritage Information Management System (AHIMS) or State specific databases such as the Queensland Heritage Register that deal with cultural, natural and Indigenous heritage data are often too complicated (Logan, 2013). Even though these systems deal with a variety of issues including indigenous land rights management or aural history, most are inadequate and disconnected from other national systems (Department of the Environment, 2011; NSW Aboriginal Land Council, 2010). In extreme cases such as the Australian Capital Territory and Tasmania heritage information is even managed in Excel Spreadsheets without any visible framework or use of comprehensive databases (see Figure 1) (Ballsun-Stanton, 2012; Haubt, 2012).

If we dig deeper into the decentralized Australian heritage system we can find hundreds or possibly thousands of databases within university, research, parks, community and other public and private archives. While no apparent standardized structure is evident, no detailed analysis or effort has been taken to date to bring these archives together. At the Australian Archaeological Association Conference in 2013 a designated session proposed the assigning of a task group to focus on the issue but to date no formalized output has been generated (Kirkwood, 2013; Nichols, 2013 ). 


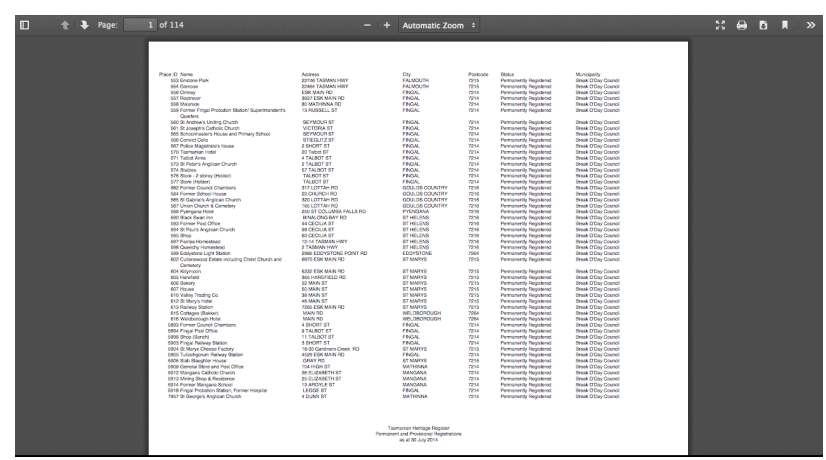

Figure 1. Tasmanian Heritage Register is a simple spreadsheet

2.2.4 The use of reference and domain models in rock art applications: Looking at the specialised field of rock art a similar picture emerges. While efforts have been undertaken for best practice research through eg the Rock Art Stability Index (RASI) no standards have been introduced within the field to date (Whitley, 2011). While guides are written for fieldwork research the question of how this data gets integrated into a centralized national or global system remains.

In 2011 McNeil and Taçon compiled the Rock Art Website Resource Kit with over 100 rock art related websites, databases and archives (McNeil, 2011). An analysis showed that a lack of consistency as well as inadequate data storage within these online presences made it impossible to share data across platforms (see Figure 2) (Haubt, 2012).

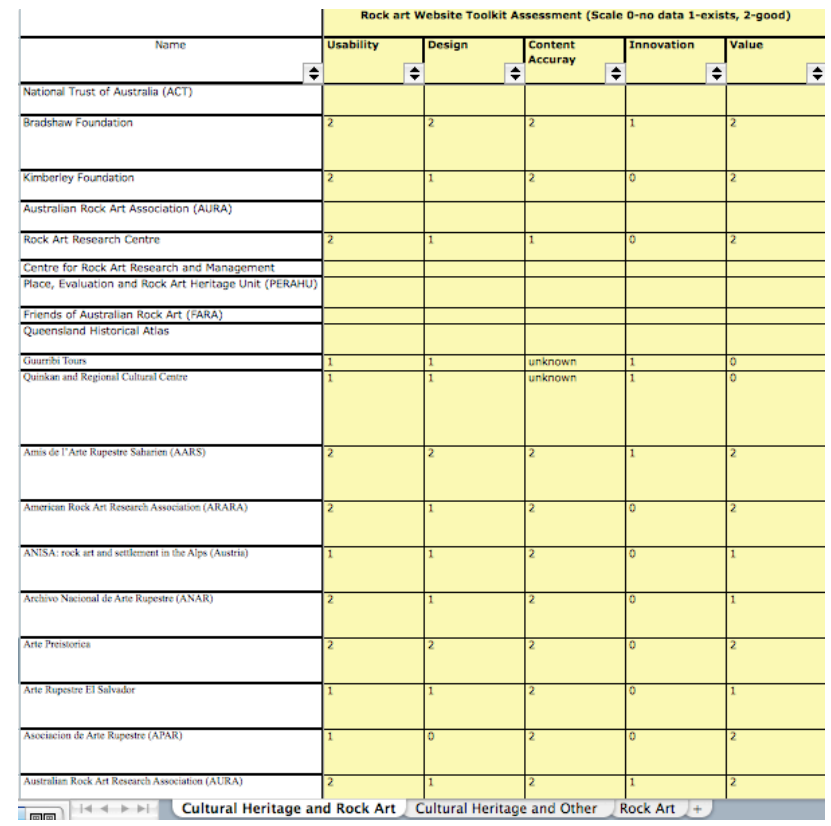

Figure 2. Analysis of McNeil \& Taçon List of Rock Art

Website Resource Kit shows inconsistency and inadequate data storage

\subsection{The Rock Art Database (RADB)}

With no consistent rock art or national Australian heritage framework to work with the RADB uses the CIDOC CRM as a reference model for the database design. The system aims to comply with the CIDOC CRM certificate standards while introducing a flexible management system that allows for the integration of CIDOC CRM compliant and non-compliant projects through an agile development approach.

The RADB further produces a Domain Model with concrete data examples collected from a range of heritage bodies and rock art projects. The Domain Model provides real world examples while the CIDOC CRM provides the framework towards a CIDOC CRM Certificate compliant system.

\section{METHODOLOGY: THE RADB FRAMEWORK}

\subsection{The RADB Universe}

Before we start looking deeper into the RADB as a whole we first need to define its roles and functions. The RADB as an organisation exists on multiple levels each producing different outputs in different stages. These levels are described in the RADB Universe Tiers $1-3$ which have been adapted from the DL Universe model (European Commission Information Society and Media, 2011):

\section{Tier 1: RADB}

The Rock Art Database (RADB) is a virtual organization that aims to bring together professionals and members of the general public to collect, manage, disseminate and discuss rock art.

\section{Tier 2: RADB System}

The RADB System offers a semantic Rock Art Reference Model (RARM) that can be implemented across international rock art projects while complying with the CIDOC CRM certificate requirements.

\section{Tier 3: RADB Management System}

The RADB Management System is the deployed online portal of the RADB using the RADB System. The portal allows users to collect, manage, disseminate and discuss rock art information through specialized functionalities using rich media content and communication tools.

This paper focuses on the 'Tier 2: RADB System', which is described in more detail in the following sections.

\subsection{The Project Development Stages}

The overall project takes an agile development approach to allow for flexibility and the ability to respond to emerging needs throughout the development of the RADB System and Management System. The development can be broken down into 5 Stages:

\section{Stage 1: Data Collection}

The first stage of the project produces a literature review of current management and technological trends within cultural heritage and rock art based on primary and secondary sources. Primary and secondary data includes relevant literature from books, journals, publications and conferences.

Further existing heritage and rock art projects, as well as relevant databases and archives are analysed to contextualize findings in existing systems.

\section{Stage 2: Conceptual Model Design}

Results from the data collection are reviewed to inform the Feature-Driven Development process (FDD) and Agile Development Approach and 
produces a conceptual Rock Art Reference Model (RARM) for the RADB System.

\section{Stage 3: Development}

The development of the Database Management System follows an Agile Development approach. The approach considers four layers of data abstraction (Oppel, 2010):

\section{The Rock Art Reference Model (RARM) Compliance with the RARM \\ 1. The Physical Layer Physical Data Independence \\ 2. The Logical Layer Logical Data Independence \\ 3. The External Layer}

\section{Stage 4: Deployment, Testing and Analysis}

The database system is made accessible but limited to relevant research participants. The testing process is used to monitor the performance of attributes, user requirements and database architecture and necessary adjustments are made where applicable based on an Agile Development approach.

\section{Stage 5: Presentation of Results}

Results from Stage 4 are formalized and made available for review to assist with the improvement of the system based on the Agile Development Approach.

While this paper focuses on the development of the RADB System described in Stage 2 The Conceptual Model Design, it is important to understand the RADB System as part of an Agile Development cycle within these 5 project development stages which is frequently reviewed and improved.

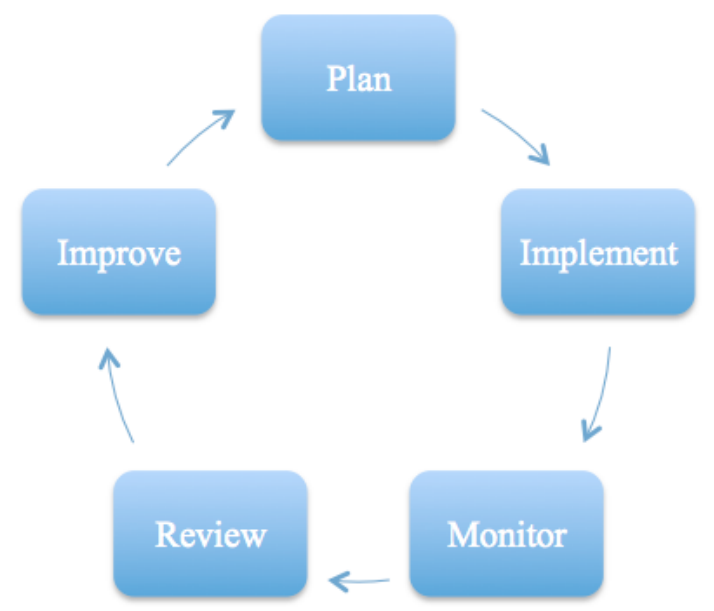

Figure 3. Agile Development approach using the PIMRI Cycle in the RADB project development
3.2.1 Agile Development Approach: The project development follows an Agile Development approach within a PIMRI cycle. Agile software development describes a dynamic software development approach rather than a linear approach and assist with flexibility and improving system performance within a quality framework. The agile approach is characterised through undergoing a frequently repeating development cycle based on PIMRI (Plan - Implement - Monitor - Review Improve) (see Figure 3).

The agile approach as a result produces results within each PIMRI cycle in contrast to a linear start to finish approach. This allows for project development stages one to five to be revisited and redefined as part of the continuous development cycle.

\subsection{The RADB System}

The Rock Art Database System is the second Tier within the RADB Universe. It describes the development phase of the Rock Art Reference Model document (RARM) that is used to inform the RADB System. The RADB System does not produce a physical database but rather seeks to inform such systems through the use of a semantic reference model as well as providing concrete examples of applied systems.

The aim of integrating both semantic and concrete models is to improve understanding of the system by providing examples within a theoretical context. The examples can then further be used to improve and inform a rock art specific reference model through use case, user story within a Feature-Driven Development process.

The RARM is produced in three stages:

\section{Use of CIDOC CRM}

2. Development of a rock art specific Domain Model

3. Mapping the CIDOC CRM against the Rock Art specific Domain Model (see Figure 4)

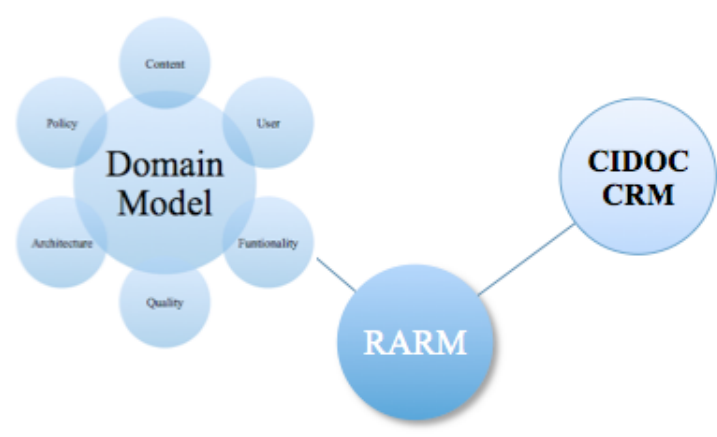

Figure 4. The RADB System

3.3.1 The Rock Art Reference Model (RARM): The Rock Art Reference Model (RARM) aims to provide a document in form of a reference model for rock art documentation and management that can be used within a variety of applications across a wide range of platforms. In the RADB project it is used to inform the design of the RADB Management System.

The RARM integrates two documents:

The CIDOC CRM which provides a semantic reference model to allow flexibility, compatibility and integration of 
resources on a global scale within the greater heritage sector.

The Domain Model which provides a collection of data fields, entities and attributes. The domain model in contrast to the CIDOC CRM provides concrete examples of data fields in a range of relevant existing projects.

3.3.2 The use of the CIDOC CRM: The CIDOC CRM is used as the foundation for the reference model similar to the use of the CRM in the Digital Library Reference Model (European Commission Information Society and Media, 2011). It provides a semantic framework within which the rock art reference model can operate.

The aim of the use of the reference model is not to tie it to any technologies or definite details such as data fields but to supply common semantics that provide a high level of flexibility that can be used in a variety of applications. The model describes entities and their relationships in order to clarify issues within international, national and local heritage documentation. It provides a flexible system that aids the process of finding potential solutions for a variety of research questions. The system further allows rephrasing research questions in order to be able to explore particular issues from different angles (OASIS, 2015).

Use of the CIDOC CRM will:

- enable the integration of resources in the greater heritage sector on a global scale

- enable the integration of rock art resources on a global scale

- create standards for objects and relationships within the model

- $\quad$ assist with identifying needs by breaking down larger problems into smaller problems that can be clarified and refined

- improve communication between professional and disciplines

- $\quad$ assign roles and responsibilities

- compare things and enable discourse towards best practices

3.3.3 The Domain Model: In contrast to the CIDOC CRM the Domain Model informs the specific needs for the RADB System including data fields, entities and attributes. The domain is broken down into constituent domains in which the RADB System seeks to operate. For the purpose of the breakdown the model adapts the Digital Library domain model breakdown (European Commission Information Society and Media, 2011).

Content: The content domain consists of a collection of primary objects and metadata of existing projects. The content is broken down into the following categories.

- Heritage Bodies Management Systems: A collection of data fields and relationships based on heritage reporting mechanisms from UNESCO World Heritage List Application to National and Local Jurisdiction requirements.

- Resources Management Systems: A collection of data fields and relationships from relevant systems including but not limited to library, museum and university archival systems and the Archaeological and Architectural Heritage Core Data Standard (CDS).
- Rock Art Management Systems: Selected data fields and relationships obtain from literature, the rock art website resources kit, relevant fieldwork data from selected projects and the Rock Art Stability Index (RASI).

- Other Public and Private Management Systems: Selected data fields and relationships obtained from other relevant online resources.

- Communication Systems: For the creation of module packages for integration of eg Facebook, Instagram, Flickr, LinkedIn, Youtube but also Google Docs and Academia

- Information and Communication Technology: Integration of technical specifications and metadata of eg text, image, video, sound, 3D, GIS but also applied computer technologies eg scripts, coding etc.

Functionality: The function domain consists of system and user defined functions. It encompasses relationships between information objects, metadata or users and is concerned with data interpretation and dissemination.

Users: The user domain consists of a range of possible functions a user can have within the system. It manages user profiles and associated privileges, restrictions and groups.

Quality: The quality domain is concerned with evaluating the system in its entirety and encompasses content, functionality, users, architecture and policy content.

Architecture: The architecture domain is described in the RADB system and mapped within the Rock Art Reference Model.

Policy: The policy domain is concerned with the governance of the system. It describes set rules, conditions, terms and regulations within the RADB system.

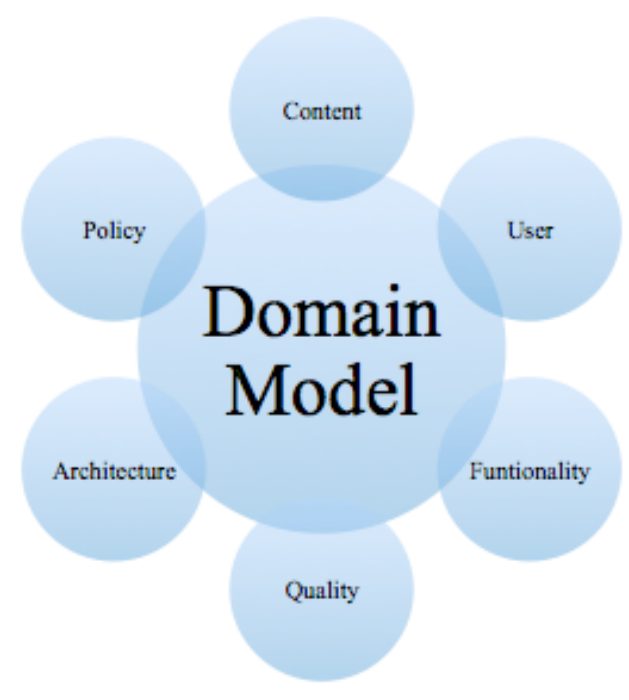

Figure 5. The Rock Art Domain Model 
3.3.4 The RARM Mapping Process: The final step is to map the CIDOC CRM against the Domain Model to produce the RARM. Popular methods for CIDOC mapping have been the Monument Inventory Data Standard (MIDAS) approach or the Dublin Core (Doerr, 2011). The RARM uses the Dublin Core method in two approaches (Stead, 2008).

The first approach uses the Dublin Core Metadata set approach and produces a mapping chart (Stead, 2008; Iworx Ltd. Greece, 2015; Richards, 2015). The chart is used to develop an understanding of how specific information objects might fall into multiple CRM entities or properties. This approach is useful to understand the relation between information objects. By understanding the relation between objects they can be more appropriately queried and assigned within the system (see Figure 6).

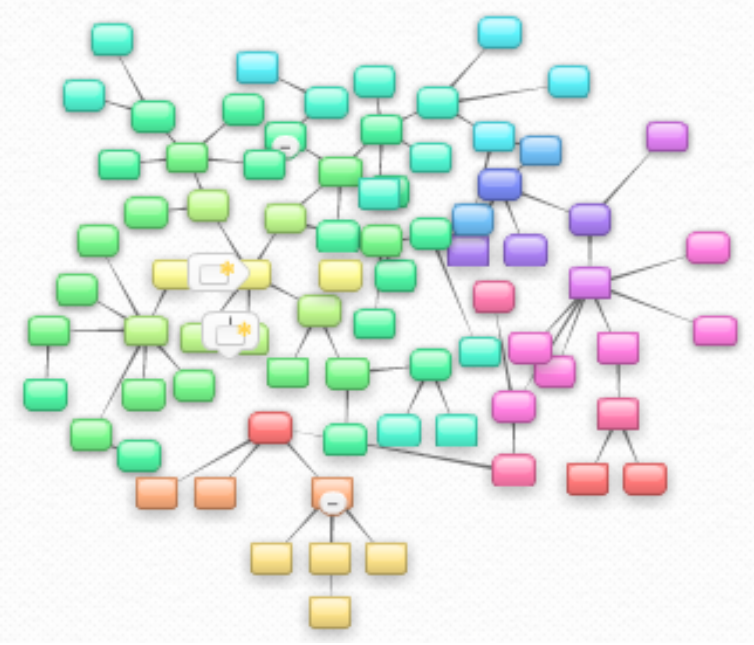

Figure 6. Chart used to map entities and attributes in RARM helps understand relationship models

The second approach produces a spreadsheet. Within the spreadsheet individual data fields and relationships are mapped against the CRM entities and properties. This mapping concept helps to produce fields that can be used for deployment within the database (see Figure 7).

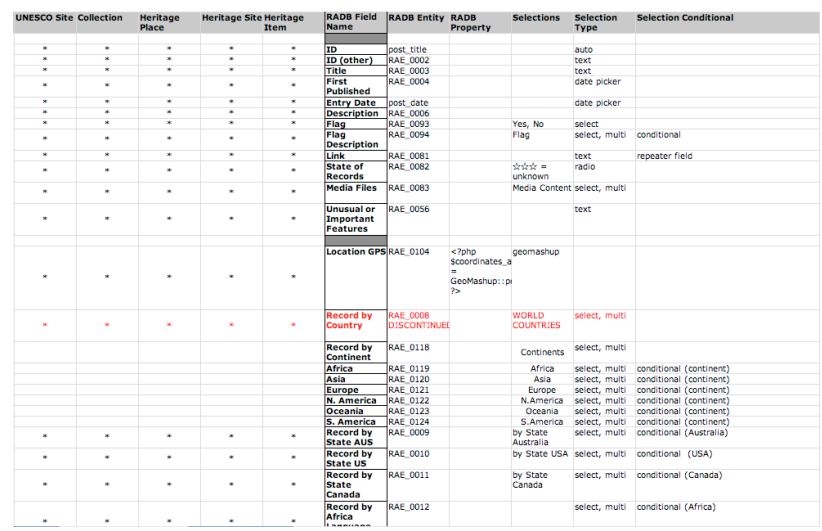

Figure 7. Spreadsheet used to map CIDOC CRM against Domain Model helps understand use of specific data fields

\section{USE OF THE RADB SYSTEM IN THE RADB MANAGEMENT SYSTEM}

The RADB System was implemented in the RADB Management System design and released as a proof of concept model in June 2014 under the rockartdatabase.com domain (see Figure 8). The system's use is restricted until July 2015 for testing purposes. Current users are able to browse and search existing data but are not able to add content to the database; this feature is limited to a group of test users.

Tests within the last 6 months have primarily focused on the flexibility of the RADB System regarding statistical evaluations concerned with the Domain Content, Functionalities, Users and Policies. The system currently incorporates over 200 rock art projects with varying levels of data integration.

Further reporting tools have been generated and successfully deployed based on the State of the Environment Reports of the Australian Department of the Environment as well as state departments.

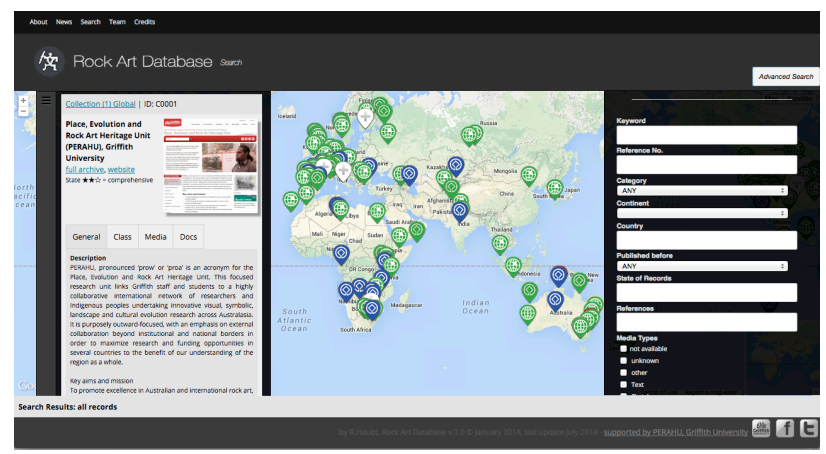

Figure 8. The RADB Management System

\section{CONCLUSION}

The development of the RADB System and the RARM document allowed for a better understanding of the RADB Management System requirements for heritage professionals and IT professionals alike. While the CIDOC CRM provides the general oversight of global heritage problems allowing to break down larger problems into smaller manageable packages, the creation and use of the rock art specific domain model RARM allowed developing a greater understanding of individual needs within the specialised field.

The use of the CIDOC CRM gives the RADB System a flexible structure that has proven to be easily customizable to cater for individual needs within a global system. Problems still occur within the mapping process where it is often difficult to assign data to the appropriate entity or property within the CRM as it is sometimes unclear which entity best to use for particular issues. Producing charts and spreadsheets based on the Dublin Core approach has been helpful but has not fully solved all of these issues. To improve mapping techniques future implementations will investigate other methods such as the MIDAS approach.

The Rock Art specific Domain Model has been particularly useful to clarify user roles and helped to better understand specific tasks assigned to particular roles within greater project responsibilities. The user domain is currently undergoing a review to optimize integration of user profiles for the implementation of social network functionalities to improve communication and crowd sourcing capabilities. 
Using an Agile Development approach in conjunction with the Reference and Domain Model allowed for a more responsive development process. New user requests within each iteration frequently test the system's flexibility and allow to develop a deeper understanding of the correlation between user needs and the systems framework. The agile approach further assists with maintaining a quality framework through frequent revision processes.

One of the greatest ongoing challenges to date within this project remains obtaining Australian rock art and indigenous heritage specific information from national, state, community and local archives. This effected the optimization and streamlining process of data for the RADB. The development of a rock art specific domain model has assisted with a better understanding of the urgent need to improve existing tools for managing heritage data. As already suggested at the Australian Archaeological Conference in 2013 this paper proposes the forming of a task group to help improve Australian heritage management through the development of a national reference model. The paper further proposes the forming of a rock art specific task group similar to UNESCO's World Rock Art Archive group with focus on further developing the Rock Art Reference Model in conjunction with the IFRAO.

The RADB further seeks to find support within the national and international rock art community to assist with future development of the Rock Art Database project with the aim to grow a sustainable platform free to use for rock art enthusiasts and professionals around the globe.

\section{REFERENCES}

\section{References from Journals}

Aubert, M., Brumm, A., Ramli, M., Sutikna, T., Saptomo, E., \& Hakim, B. et al., 2014. Pleistocene cave art from Sulawesi, Indonesia. Nature, 514(7521), 223-227.

Logan, D., 2013. Inventories and Heritage Management, The Australian Experience. Conservation Perspectives, The GCI Newsletter, 28 (1), p.12.

Vileikiis, O. e., 2012. Information Management Systems for Monitoring and Documenting World Heritage - The Silk Roads CHRIS. International Archive of the Photogrammetry, Remote Sensing and Spatial Information Sciences, Melbourne, Australia, XXII ISPRS Congress, 25 August - 01 September 2012. Volume XXXIX-B4, pp. 203-208.

Walt, H. e., 1997. The International Rock Art Project. Rock Art Research, 14, pp. 44-50.

\section{References from Books}

Fidler, R., 1997. Mediamorphosis. Sage Publications, Inc.

Lock G.R., 2003. Using Computers in Archaeology: Towards Virtual Pasts. Routledge. London, UK.

Oppel, A., 2010. Databases Demystified (2nd Edition ed.). McGraw-Hill Osborne Media, pp.4-7.

Whitley, D., 2011. Introduction to Rock Art Research. Left Coast Press, Inc. Santa Fe, USA, pp. 1-18.

\section{References from Other Literature}

Carlisle, P. e., 2014. The Arches Heritage Inventory and Management System: a standards-based approach to the management of cultural heritage information. Paper presented at the CIDOC Conference: Access and Understanding Networking in the Digital Era, Dresden, Germany: The Getty Conservation Institute, 6-11 September 2014, p. n.pag.

CES VIC (Commissioner for Environmental Sustainability Victoria), 2013. State of the Environment Report 2013. The State of Victoria. Australia. p. n. pag.

Department of the Environment, 2011. State of the Environment Report 2011. Australian Government, Department of the Environment, Section 9; 4.5 Outcomes, pp. 695-792; 774-779.

Haubt, R.A., 2013. Virtual Heritage Archives: Building A Centralized Australian Rock Art Archive, Int. Arch. Photogramm. Remote Sens. Spatial Inf. Sci., XL-5/W2, 319324.

Kirkwood, Luke., 2013. The Case for National Reform: A Comparative Global Assessment. AAA 2013 Conference, Complexities of Scale, 1st-4th December 2013. Coffs Harbour. Australia. n.pag.

Nichols, Stephen., 2013. What is archaeology for? Lessons for QLD about the Future of Cultural Heritage Legislation in Australia. AAA 2013 Conference, Complexities of Scale, 1st4th December 2013. Coffs Harbour. Australia. n.pag.

NSW Aboriginal Land Council, 2010. Methods of Protection: Cultural Heritage Database Register. Caring for Culture: Perspectives on the Effectivness of Aboriginal Cultural Heritage Legislation in Victoria, Queensland and South Australia, p.49.

NSW EPA (New South Wales Environment Protection Authority), 2012. State of the Environment Report 2012. New South Wales Government. Environment and Heritage. Environment Protection Authority. Australia. 2012. pp. 70-74.

NT EPA (Northern Territory Environment Protection Authority), 2013. State of the Environment Report 2013. Northern Territory, Environment Protection Authority. NSW Government. Australia. n. pag.

OCSE (Office of the Commissioner for Sustainability and the Environment), 2012. State of the Environment Report 2012. Australian Capital Territory. Australia. pp. 552-554; 553.

QLD EHP (Queensland Department of Environment and Heritage Protection), 2011. State of the Environment Report 2011. Queensland Government. Australia. pp. 161-165.

SA EPA (South Australian Environment Protection Authority), 2008. State of the Environment Report 2008. Environment Protection Authority. The Government of South Australia. Australia. pp. 280-294; 290-291.

WA EPA (Western Australia Environmental Protection Authority), 2007. State of the Environment Report 2007. The Government of Western Australia. Australia. pp. 225-239; 234.

\section{References from Websites}

Ballsun-Stanton, B., 2013. Flat Files have Always Been Good Enough: An Arguement for more naunced data structures. FAIMS Project, AAA (Australian Archaeological Association) 


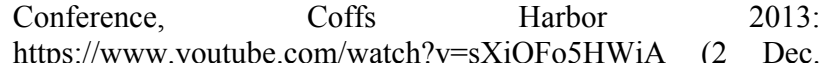
2013).

Ballsun-Stanton, B., 2012. Oportunities and Issues of Data Federation. FAIMS Stocktaking Workshop 2012, Conference Proceedings. https://fedarch.org/pdf/ConferenceProceedings.pdf (28 Feb. 2015).

Doerr, M., 2011. The EDM Model. CIDOC CRM. http://www.cidoc-crm.org/crm_mappings.html (1 Sep. 2012).

EPA TAS (Environment Protection Authority Tasmania), 2009. State of the Environment Report 2009. Tasmanian Planning Commission. The Government of Tasmania. Australia, http://www.planning.tas.gov.au/library_and_information/state_ of the environment_reports (1. Feb 2015).

European Commission Information Society and Media, 2011. COAR Repositories. (N. N. Candela, Ed.). DL.org: Coordination Action on Digital Library Interoperability, Best Practices and Modelling Foundations : https://www.coarrepositories.org/files/D3-2b-Digital-Library-ReferenceModel.pdf (24 Feb 2015).

Foster, M., 2011. Protect Australia's Spirit, a campaign to save our rock art. Australian Broadcast Corporation, Australia http://www.abc.net.au/site-

archive/rural/telegraph/content/2011/s3231725.htm (1. May 2012).

Gore, A., 1998. The Digital Earth. Understanding our Planet in the 21st Century, California Science Center, Los Angeles: http://www.isde5.org/al_gore_speech.htm (1 Jan 2013).

HuNI, 2015. HuNI Linked Data - first datasets | NeCTAR. www.nectar.org.au/news/sub-projects/huni-linked-data---firstdatasets (28 Feb. 2015).

ICOM/CIDOC Document Standards Group, CIDOC CRM Special Interest Group. (2015, 01 27). Definition of the CIDOC Conceptual Reference Model. (P. D. Le Boef, Ed.) http://www.cidoc-

crm.org/official_release_cidoc.html\#CIDOCCRM6.0 (28 Jan 2015).

Iworx Ltd. Greece, 2015. CIDOC CRM Mappings, Specializations and Data Examples. The CIDOC CRM. www.cidoc-crm.org/crm_mappings.html (28 Feb 2015).

McNeil, C., Taçon P.S.C., 2011. Rock-Art Website Resource Toolkit. (version 1.0). Southport: Griffith University. Available: http://www.griffith.edu.au/ data/assets/pdf file/000 5/397346/Rock-art-website-resource-kit.pdf. (1 Feb 2012).

Mark, D., 2011. Calls for A National Rock Art Database. Australian Broadcasting Corporation News. http://www.abc.net.au/news/2011-05-31/calls-for-national-rockart-database/2738606 (30 Mar. 2011).

Mason, I., 2012. Crm-sig CIDOC-CRM in Australian humanities virtual laboratoryproject: HuNI. lists.ics.forth.gr/pipermail/crm-sig/2012-October/001864.html (28 Feb. 2015).

OASIS, 2015. OASIS SOA Reference Model. OASIS SOA Technical Committee. OASIS Open: https://www.oasisopen.org/committees/soa-rm/faq.php (23 Feb. 2015).
Richards, J., 2015. Richards Interoperability Federation. https://fedarch.org/slides/04_Federation/Richards_interoperabili ty federation.pdf (28 Feb. 2015).

Stead, S., 2008. CIDOC CRM. Tutorial. http://www.cidoccrm.org/cidoc_tutorial/ (25 Feb 2015).

Unesco World Heritage Centre, 2010. UNESCO World Heritage. Rock Art, World Rock Art Archive. http://whc.unesco.org/en/rocktart/ (1 Feb. 2012).

Verhoeven, D. e., 2013. Humanities e-Research at a National Scale; the HuNI Virtual Laboratory. https://eresearchau.files.wordpress.com/2013/08/eresau2013_su bmission_95.pdf (28 Feb 2015). 